\title{
Apuntes sobre ética y ciencia social: A vueltas con la cuestión del compromiso (I)
}

\author{
LUIS DE LA CORTE IBÁNEZ \\ Universidad Autónoma de Madrid
}

Primera parte: Compromiso y ciencia social: Elementos para una definición del problema

Deberíamos obtener, si fuésemos sensatos, la certidumbre de una existencia mejor y la esperanza de alcanzarla por el ejercicio cotidiano de nuestra voluntad.

Charles Baudelaire

\section{Introducción}

Se ha hablado con frecuencia del carácter "comprometido" de ciertos pensadores, artistas o escritores, para destacar en ellos una actitud crítica o inconformista respecto al mundo que les rodea o un esfuerzo público y continuado por orientar su misma actividad según determinados valores morales, generalmente vinculados también a un ideal de sociedad. Así, por ejemplo, hoy en España, la idea del compromiso del intelectual ha vuelto a ser reivindicada, después de muchos años de olvido, como una obligación cívica exigida por la situación conflictiva en el País Vasco', como bien explica la profesora de Ciencia Política de la Universidad del País Vasco, Edurne Uriarte: "Sin quererlo, ETA le ha dado un nuevo contenido a esta palabra 
(compromiso). El compromiso vuelve a tener sentido en el País Vasco, y lo tiene en forma de lucha, cada vez más decidida y unitaria, de los intelectuales contra ETA... Cuando un grupo de asesinos aterroriza a la sociedad y mata a quienes disienten de su proyecto totalitario, no caben las distancias ni los puntos intermedios. Sólo cabe combatir a los asesinos. A eso se le llama compromiso intelectual, y en el País Vasco ha vuelto a renacer" (Uriarte, 2001).

Después de leer estas líneas queda claro, no sólo el sentido que otorgamos aquí al término "compromiso" sino asimismo a la palabra - "intelectual" - a la que aquél viene asociado, digamos, por definición. Como vio hace muchos años José Luis Aranguren, la noción del intelectual admite dos acepciones. Desde el punto de vista sociológico, intelectual es toda aquella persona que desempeña un oficio basado en el empleo de la inteligencia y/o en la creación y la promoción de la cultura. Frente a esta primera acepción Aranguren preferirá, sin embargo, una concepción del intelectual "en sentido moral" la cual haría referencia a aquellos profesionales de la inteligencia que, exigiéndose a sí mismos algo más que la necesaria "profesionalidad", adoptaran una posición crítica respecto al sistema social establecido y sus contradicciones.

No es ocioso recordar que cuando Aranguren hablaba de ese "compromiso" con la sociedad solía considerar a los "cultivadores de las ciencias sociales" como un grupo de trabajadores intelectuales que "forzosamente" deberían asumir el sentido moral de su ocupación. ¿Podría hablarse entonces de "compromiso" en la ciencia social? Esta es la cuestión de la que nos vamos a ocupar en adelante. Para hacerlo comenzaremos delimitando una definición tentativa del concepto de "compromiso". A partir de ahí, nuestra reflexión discurrirá acerca de las posibilidades reales en las que el compromiso de una persona o un grupo de personas con unos valores e ideales concretos podría llegar a impregnar su actividad como científicos sociales. En resumen, este texto se propone los siguientes objetivos fundamentales: (1) afrontar la cuestión polémica sobre si, en efecto, el compromiso del científico social es o no posible o incluso deseable; (2) ofrecer una cierta propuesta moral que pueda guiar el desarrollo de cualquier ciencia social; (3) realizar una descripción mínima de las vías que consideramos hoy pertinentes para realizar esa misma propuesta o cualquier otro forma de compromiso desde el ámbito de la ciencia social. 
Sorprendentemente, nociones tales como las de compromiso u otras parecidas, es decir, nociones de carácter moral, no han gozado de excesiva aceptación en el ámbito general de las ciencias. Por eso, dos primeras cuestiones a las que habremos de responder son las de si, tal y como muchos científicos y pensadores ilustres han supuesto, la ciencia es y deba ser una actividad "libre de valores", por utilizar una expresión bastante frecuente. Por supuesto, a estas alturas el lector habrá anticipado nuestra oposición a esta concepción de la ciencia, ya que de considerarla cierta seguramente no valdría la pena seguir escribiendo pero le pedimos que no sea impaciente y atienda a nuestros argumentos; después de todo, no basta con tener una opinión para que esta pueda considerarse como razonable, sino que siempre es necesario fundamentarla, dotarla de argumentos que la sostengan, justo lo que pretendemos hacer aquí. Antes de iniciar esa labor de "fundamentación", no obstante, es necesario precisar en qué sentido concreto vamos a hablar y vamos estudiar este asunto del compromiso.

\subsection{El punto de vista moral}

Desde luego, no deben ya quedar dudas respecto a cuál es el único punto de vista desde el que podríamos encarar la cuestión del compromiso y la ciencia social: el punto de vista de la moral. En términos más técnicos podríamos afirmar que reflexionar sobre el compromiso implica entrar en el terreno de la ética, una disciplina generalmente vinculada a la filosofía, aunque de creciente orientación interdisciplinar. ¿Acaba con esto las ambigüedades?. Realmente no, porque para hablar de ética habría que precisar qué se entiende por tal cosa y cuál sea su objeto de estudio, cuestiones sobre las que no existe un consenso unánime entre los propios expertos.

En primer lugar, hay que precisar qué se entiende por moral. El ámbito de lo moral tiene diversos niveles. Como explicó Xavier Zubiri hace muchos años, lo moral puede definirse en un principio como un atributo del hombre que le distingue de entrada respecto a las otras formas de vida existentes. A diferencia de los animales, cuyo comportamiento se encuentra determinado por la interacción entre sus capacidades biológicas y los estímulos del medio, este ajustamiento perfecto al entorno desaparece en el caso de los seres humanos quienes, por causa de su misma evolución biológica (sobre todo cerebral), gozan 
de una parcial libertad respecto a los estímulos, viéndose así en la obligación de "hacerse cargo" de su situación real y determinar por sí mismos cuál deba ser la respuesta adecuada. Con todo esto queremos decir, ni más ni menos, que el hombre es el único animal que para actuar, para vivir, necesita "justificar" sus acciones (su vida, en definitiva), esto es, tomar opción por lo que estime como "justo" o "bueno" y a rehuir lo que considere como "malo" o "injustificable". Es también por esto que se suele decir que las acciones, que la vida que tienen un "sentido" $y$, como dice Aranguren, "ese sentido de la vida es precisamente lo que llamamos moral" (Aranguren, 1994, p. 184).

Desde este punto de vista, por tanto, no habría acción humana amoral, excepción hecha de aquellas conductas de carácter reactivo que resultan absolutamente incontrolables o ajenas a nuestra voluntad y que, en ocasiones, nos reducen al nivel de complejidad de las especies animales inferiores". Esta sería, siguiendo a Zubiri, la "moral como estructura", expresión con la que se pretende subrayar el carácter constitutivamente moral de la vida humana. Es de especial interés añadir aquí que la estructura moral se especifica a través de actos, pero también del encadenamiento de estos en forma de caracteres, hábitos y formas de vida, los cuales son igualmente susceptibles de valoración moral.

En un segundo nivel, lo moral hace referencia a ciertos contenidos normativos y valorativos que dotan a la acción humana de la inevitable "justificación" a la que aludíamos hace un momento. Es la "moral como contenido", la cual trata de especificar la naturaleza del "bien" y del "mal", de lo "justo" y lo "injusto", en suma, de lo moral y lo "inmoral". Ahora bien, el contenido de la moral procede de fuentes diversas ("inclinaciones" naturales, tradiciones culturales y religiosas, imposiciones sociales, etc.) que, al menos en principio, se nos imponen por razones de su vigencia social. Sobre tal "imposición" aún cabría superponer una tercera dimensión de la moral, a la que llamaríamos "moral como actitud", que nacería de un cierto inconformismo con los contenidos de la moral recibida o impuesta dando lugar a una deliberación racional primeramente orientada a la crítica de la moral vigente $y$, luego, a la justificación racional de una nueva "propuesta" moral. Sólo al llegar a este tercer nivel, habríamos entrado en el espacio de la ética o la llamada "razón práctica". 
Como puede comprobarse, para que la ética sea posible hay que dar por supuesto que el hombre es un ser libre, dotado de razón y responsable de sus actos. La razón hace posible la autonomía moral, es decir, la libertad de decidir, más allá de coacciones de todo tipo, cuáles deban ser las normas, valores o principios morales de hayan de orientar nuestra conducta y los hábitos y formas de vida de deban derivarse de aquéllas. Dada su legítima pretensión de explicar las acciones humanas en términos de causas y leyes, de determinaciones más o menos universales, los científicos sociales han sido siempre especialmente reticentes a asumir como real el hecho de la autonomía moral (tal vez sea esta una de las razones por las que siempre nos ha resultado tan difícil abordar el tema de las relaciones entre ética y ciencia social). Pero es importante insistir en que una concepción absolutamente determinista del fenómeno humano que negase la frágil pero siempre posible capacidad del hombre para superar impulsos biológicos y coacciones sociales y de obrar según criterios libremente asumidos supone una perspectiva antropológica incompatible con la Etica. Al fin y al cabo, si toda experiencia humana estuviera determinada de antemano de nada serviría reflexionar sobre lo que sería bueno que hiciéramos o dejáramos de hacer pues nuestras acciones seguirían siendo independientes de nuestros pensamientos y deseos ${ }^{3}$. El determinismo absoluto podría actuar como un ácido capaz de disolver toda noción de responsabilidad personal y colectiva, entregándonos a la pasividad o a la indolencia y transformándonos a nuestros propios ojos en marionetas de un supuesto destino inescrutable, ya sea de carácter "natural" o "divino"4.

Como bien ha demostrado la propia ciencia social en sus investigaciones sobre las llamadas profecías autocumplidas, la creencia en la irreversibilidad del destino o en los inescrutables designios de un cierto dios o de la propia naturaleza "realiza" el determinismo que dichas creencias anuncian. Por el contrario, como afirma Fernando Savater, el propósito de toda reflexión moral sólo se justifica, precisamente, como un "rechazo a la indiferencia", es decir, a la idea de que el mundo es (sólo) lo que es y que al ser humano (únicamente) le corresponde dejarse llevar por las leyes naturales, históricas, sociales o psicológicas. En este sentido, insiste también este mismo autor, se vuelve imprescindible asumir que el primer requisito para "ser moral" 
es "tener mucha moral", o sea, creer en la posibilidad de elegir con algún grado de libertad lo que se quiere hacer.

¿Cuáles son las implicaciones que este punto de vista moral conlleva a la hora de analizar el fenómeno social de la ciencia? Por supuesto, fuera de tal perspectiva no sería realmente lícito pensar que el científico tuviera oportunidad alguna de subvertir las presiones de la naturaleza, la sociedad o la historia, entidades encargadas de dar dirección y sentido a las dinámicas de producción, distribución y consumo del conocimiento científico. $Y$ no han faitado, en efecto, insignes pensadores y científicos que se hayan atrevido a explicar tales dinámicas como la consecuencia necesaria e inevitable de la natural pasión humana por el conocimiento, las exigencias evolutivas de nuestra especie o el despliegue inevitable de la razón en la historia. Sin obligarnos a negar la importante porción de verdad que pueda contener tales explicaciones sobre el desarrollo y la evolución de la ciencia, la adopción del punto de vista moral nos forzaría a incluir en el análisis de tales procesos el supuesto mismo de la "autonomía moral" de las personas que, en cuanto profesionales de la ciencia, la hacen posible. Se trataría, en último término, de tomar en cuenta la posibilidad de que el científico asumiera como responsabilidad suya las consecuencias sociales de su profesión, tanto en lo que concierne al desarrollo del conocimiento como a su aplicación. Puesto en esa tesitura, sería entonces cuando el científico estaría en condiciones de reflexionar sobre cuál debiera ser el tipo de valores y proyectos morales con respecto a los cuales querría "comprometer" su propia actividad. Por tanto, un auténtico compromiso sólo podría tener lugar una vez que el científico alcanzase una cierta madurez moral, aquello a lo que Kant se refería al hablar del tránsito de una conciencia moral heterónoma, basada en la tradición, la costumbre y la obediencia a la autoridad, a una conciencia moral autónoma sostenida fundamentalmente sobre la razón, es decir, sobre la asunción reflexiva y libre de coacciones de una determinada propuesta moral. A esta condición autónoma de una cierta perspectiva moral la podemos contemplar también como la primera "virtud moral" a la que algunos autores se han referido con la palabra "autenticidad".

Ahora bien, reconocer en la figura del científico el modelo de un sujeto potencialmente autónomo y responsable, de un "sujeto moral" en sentido fuerte, no puede llevarnos al extremo de negar su inevitable inserción en una red de múltiples relaciones sociales y la influencia de 
esa red en sus propias opciones y decisiones prácticas. Como demuestran la historia y la sociología de la ciencia, la mediación institucional de la actividad científica resulta insoslayable, no solamente como posible fuente de conflictos morales entre los proyectos de la institución y los del propio científico, sino antes que eso, como verdadera condición de la existencia de la ciencia. En consecuencia, cualquier reflexión moral en torno al fenómeno da la ciencia, habrá de atender a dos dimensiones: (1) la del científico como individuo dentro de una institución y (2) la de la institución como conjunto de individuos implicados en un proyecto (que, a su vez, debe remitirnos a las relaciones de esta clase instituciones con otras de naturaleza social diversa: políticas, económicas, militares, etc.). Ambas dimensiones pueden y deben ser concebidas como lugares en los que se concreta la condición constitutivamente moral de la práctica científica en todos sus niveles. De ahora en adelante, por tanto, cuando hablemos del (posible) compromiso del científico estaremos refiriéndonos primariamente a cada científico como sujeto moral potencialmente autónomo pero también por extensión a los posibles grupos de científicos o a la comunidad científica en general en cuanto sujeto colectivo al que atribuimos la misma capacidad de la que goza el sujeto individual para orientar sus acciones de modo autónomos.

\section{Ciencia y valor}

Tradicionalmente la ciencia ha sido contrapuesta a otra clase de actividades que, como la de los negocios o la política, tienden a ser "interesadas" e "impuras". La ciencia y el científico se han situado más allá del bien y del mal, especialmente del mal, debido en parte a la habitual connotación de "bondad moral" que ha acompañado siempre a la idea de "pureza" (Gracia, 1989) y en parte gracias a la asociación entre las nociones de ciencia y progreso que ha constituido una creencia fundamental de la cultura occidental, al menos desde tiempos del Renacimiento. No obstante, diversos análisis llevados a cabo en el ámbito de la Sociología, la Historia y la Filosofía de la ciencia han ido refutando estos dos mitos sobre la bondad moral de la ciencia y sobre su vinculación directa a un progreso seguro e inevitable.

La falacia de una ciencia pura, esto es, desinteresada podría empezar a cuestionarse, por ejemplo, a partir de las conocidas investigaciones 
realizadas por Robert K. Merton para revelarnos un supuesto ethos o moral de la ciencia, un preciso sistema de valores y normas (comunismo o comunalismo, universalismo, desinterés y escepticismo organizado) que regularían los procesos de investigación y producción del conocimiento al interior de las instituciones científicas. Aunque la observación de algunos de esos valores por parte de los científicos sea hoy más que discutible, la sociología de la ciencia de Merton nos pone sobre aviso respecto a imposibilidad de seguir interpretando la dinámica de la investigación científica como un proceso totalmente ajeno a principios normativos. En realidad, y como es preceptivo respecto a cualquier rol socialmente instituido, la identidad del científico siempre ha estado definida por su "compromiso" con ciertas normas y valores.

De todos modos, las normas y valores que con menos reparos se reconocen como criterios que orientan el trabajo científico, así por ejemplo las señaladas por Merton, son las normas y valores directamente derivadas de aquellas exigencias metodológicas que sólo tratan de garantizar el estatuto propiamente científico de ese trabajo; normas y valores, en suma, que nada dicen respecto a la implicaciones sociales y morales de dicho conocimiento. En verdad, la perspectiva de autores como Merton aún parece instalada en la vieja concepción de la ciencia como theoría, es decir, como pura contemplación de la naturaleza y el mundo. Pero a pesar del fuerte arraigo que esta interpretación de la ciencia ha tenido en la tradición occidental lo ciertos es que, al menos desde el siglo XVII, comenzaría a arraigar una perspectiva alternativa u opuesta, suscrita ya en el Novum Organum de sir Francis Bacon. Por primera vez, Bacon pondrá en relación los conceptos de ciencia y poder hasta el punto de afirmar que una y otra vendrían a ser una misma cosa. Bacon deducirá de esto, por cierto, que el sentido del trabajo científico no podría encontrarse entonces en la mera creación de objetos de contemplación sino que, en congruencia con la moral cristiana, el científico debería usar su ciencia para «mitigar la condición de la humanidad».

Sin duda, las reflexiones del canciller inglés en torno a la ciencia supusieron un progreso en la comprensión de la ciencia como una actividad humana más, susceptible, por tanto, de análisis moral. Pero lo cierto es que Bacon, quien dedicó su último libro a imaginar la utopía de una sociedad gobernada por principios científicos, fue uno 
de los primeros artífices del espíritu racionalista moderno que, si bien hizo posible el pleno desarrollo de la ciencia tal y como hoy se conoce, también ayudó a extender aquella desmesurada confianza en las bondades de la práctica científica que anestesió a los propios científicos respecto a las posibles repercusiones, a veces verdaderamente inmorales, de su trabajo.

No es de extrañar que fuese el gran sociólogo Max Weber, enormemente interesado en el estudio de la relación entre juicios de hecho y juicios de valor, uno de los pensadores que cambiara el optimismo moderno e ilustrado respecto a las evoluciones de la ciencia por un sombrío escepticismo. Que la ciencia y la técnica acabarán trayendo la felicidad a nuestro mundo, diría Weber al final de su vida, es un vaticinio que sólo puede seguir siendo sostenido por periodistas o por "algunos niños grandes" que ocupan cátedras.

Weber reconoció asimismo la influencia de los "valores precientíficos" en la ciencia a la hora de elegir los objetivos de estudio: en un mundo que, después de Kant, no podía concebirse sino como un infinito caos de fenómenos, la necesidad de optar entre ellos se haría inevitable y es indudable que serían los valores vigentes en cada contexto social e histórico los que determinarían dicha selección. De este modo, Weber anticipó con su habitual agudeza una de las principales ideas que los sociólogos del conocimiento explotarían más tarde y que serviría también en parte para empezar a desechar la vieja concepción de una ciencia "pura": el desarrollo del conocimiento científico no podrá entenderse nunca más como el mero resultado de la acumulación ininterrumpida de evidencias empíricas y la consiguiente evolución interna de teorías, conceptos y leyes. Habría que empezar a tomar muy en cuenta el pluralismo axiológico o moral que ya en la época del sociólogo alemán comenzaba a definir nuevas formas de relación social y de organización de la vida colectiva (ver Echeverría, 1995).

Finalmente, el reconocimiento de la falsa neutralidad de la ciencia y la técnica volverá a aparejarse en los filósofos de la Escuela de Frankfurt con un profundo sentimiento de decepción ante la trágica evolución de la historia moderna a la altura de mediados del siglo XX. La razón científica es definida por Horkheimer como "razón instrumental", instrumento al servicio de una evolución social carente 
de conciencia crítica. Por su parte, Habermas hará decisivas precisiones de la relación entre conocimiento y valores humanos, renovando también para el análisis de la ciencia la noción marxiana de praxis. Dada la apertura del hombre al mundo de los valores, su capacidad par descubrir y/o crear diversos valores, aquél desarrollará ciertos "intereses". El hombre actúa porque tiene un interés concreto y preciso para hacerlo. Pero sucede que, por una parte la ciencia constituye una cierta forma de acción, de praxis, mientras que por otra la misma praxis científica, en cuanto produce conocimiento, constituye un requisito indispensable para realizar otras clases de acción. Dicho de otro modo, Habermas, como mucho antes Bacon, se opone al enfoque contemplativo del conocimiento y la ciencia. Los procesos de producción del conocimiento buscan satisfacer diversos intereses humanos, de entre los cuales Habermas destaca un interés técnicoinstrumental o de dominio de la naturaleza y un interés racionalemancipativo o de liberación respecto a diferentes formas de enajenación social que el propio filósofo alemán propone como interés primordial para orientar el desarrollo de una ciencia social crítica.

En definitiva, el fecundo tema de la relación entre ciencia y valores ha dado mucho que pensar y hoy por hoy se admite en términos generales, no sólo que no existe ciencia libre de valores sino también que, pese a lo que opinaría por ejemplo Weber, los valores del científico siempre influyen en sus observaciones. En cualquier caso, esta segunda dimensión de la cuestión nos debe preocupar bastante menos aquí, ya que nuestro tema no es tanto el de la objetividad de la ciencia, ciertamente dificultada por su carácter no neutral, como el de su vinculación a valores e intereses extracientíficos que determinen la elección de los problemas a investigar así como los usos que posteriormente se hagan del conocimiento disponible.

\section{La evolución social de la actividad científica y la necesidad del compromiso}

Para completar nuestra acometida contra la falacia de la neutralidad de la ciencia hay que tomar en cuenta la propia evolución de las ciencias a lo largo de los dos últimos siglos, propiciada en parte por el segundo mito asociado a dicha falacia: el mito del progreso ${ }^{6}$. Tal vez podríamos caracterizar esa evolución como un proceso de progresiva institucionalización de la ciencia; práctica social que ha ido ganando relevancia 
hasta el punto de llegar a alterar los sistemas de producción de bienes y servicios de las llamadas sociedades postindustriales en favor de la producción de conocimiento, básicamente científico.

Como ya advirtió Aranguren (1995) nuestras sociedades postindustriales se caracterizan por dos rasgos fundamentales. Desde el punto de vista económico, nuestras sociedades se han convertido en lo que llamamos "sociedades de consumo" y en sociedades tecnológicas, desde el punto de vista del conocimiento, al dar prioridad a sus dimensiones prácticas de control y manipulación del mundo, como ya mostraron los análisis de la Escuela de Frankfurt.

De un lado, y desde el punto de vista de la sociedad de consumo, algunos autores han intentado explicar el proceso de producción y transformación del conocimiento científico mediante una analogía con las leyes del mercado que regulan la actividad económica en aquel tipo de sociedad (Danziger, 1990; Bourdieu, 1991; Rosa y otros, 1996). En este sentido habla Danziger de la existencia de una verdadera "economía política del saber" que permite entender cómo la actividad científica, ocupada hoy en una incesante dinámica de producción de conocimiento, responde a las leyes de un mercado constituido por el conjunto de personas que actúan como potenciales consumidores de sus productos. Consumidores que, en consecuencia, determinan el valor simbólico de tales productos epistémicos dentro de ese mercado (es decir, su validez como conocimiento objetivo). Esto significa, en primer lugar, que las instituciones científicas se ven en alguna medida empujadas a orientar su actividad en función de las demandas generadas en el mercado al que pretendan destinar el producto de su trabajo. En consecuencia, los valores en alza dentro de ese mercado podrían acabar constituyéndose como los únicos valores que ocupasen al científico.

La siguiente cuestión a responder es: ¿quiénes son los principales consumidores del mercado simbólico de la ciencia? Conociéndolos a ellos, naturalmente, podríamos averiguar, no ya los intereses generales que persigue la investigación científica, en el sentido en que Habermas hablaba de intereses, sino incluso las demandas concretas, los problemas y las aspiraciones reales que determinan la dirección de la producción científica en uno u otro sentido. Y para responder a tan decisiva cuestión hemos de atender de nuevo a ese otro gran cambio que caracteriza a nuestras sociedades postindustriales. 
En realidad, el sentido original de toda producción tecnológica, es decir de toda aplicación del método y del conocimiento científico con fines instrumentales, ha de ser concebido desde un punto de vista social y antropológico. Por un lado, toda invención técnica constituye un fenómeno cultural, una estrategia específicamente humana satisfacer las necesidades bioculturales de nuestra especie. Ahora bien, una vez que el hombre transforma la técnica en tecnología mediante la aplicación de conocimientos y métodos científicos a la solución de problemas prácticos, el proceso del desarrollo técnico se complica enormemente, al igual que le sucedió a la ciencia, institucionalizándose. Por otra parte, en la medida en que la creciente complementación entre ciencia básica y aplicada dado el hecho de que los propios avances tecnocientíficos comiencen a afectar a cuestiones tales como la seguridad y el poder de los Estados y el desarrollo económico de las naciones, se irán reforzando los fuertes lazos de dependencia entre las instituciones científicas y los poderes político y económico quienes actuarán de hecho, no sólo como los principales consumidores de los productos epistémicos y tecnológicos sino también como su inevitable fuente de financiación. Instalado en semejante escenario el científico que no se convierte él mismo en tecnólogo se transforma en muchos casos en asistente suyo, agravándose de ese modo su ya mencionada pérdida de iniciativa respecto a la formulación de objetivos para sus investigaciones.

Carlos París, un agudo filósofo español muy interesado en el estudio de las dimensiones sociales y antropológicas de la dinámica de producción científica, ha creído apropiado definir también la situación laboral del científico mediante el concepto marxiano de "alienación", pues al fin y al cabo, tal concepto remite en verdad a ese peligro que siempre entraña cualquier proceso de división o especialización del trabajo: la pérdida de su sentido último y final (ver París, 1992, 1995). Pero tal vez haya sido un pensador bastante más conservador que el propio Marx como José Ortega y Gasset quien describió de modo más clarividente y conciso el perfil del nuevo hombre de ciencia, quien ha cambiado su rol de "sabio" por el de "obrero de la ciencia". Así, en su famoso aunque polémico libro La rebelión de las masas, Ortega advierte con disgusto el doble sentido de "mecanización" y "especialización" que ha ido tomando el trabajo científico. 
Para los efectos de innumerables investigaciones - nos dice el filósofo madrileño- es posible dividir la ciencia en pequeños segmentos, encerrarse en uno y desentenderse de los demás. La firmeza y exactitud de los métodos permiten esta transitoria y práctica desarticulación del saber. Se trabaja con uno de esos métodos como con una máquina, y ni siquiera es forzoso para obtener abundantes resultados poseer ideas rigurosas sobre el sentido y fundamento de ellos. Así, la mayor parte de los científicos empujan el progreso general de la ciencia encerrados en la celdilla de su laboratorio, como la abeja en la de su panal o como el pachón de asador en su cajón (Ortega, 1998, p. 218).

No hay duda de que este proceso de desindividuación del trabajo científico conlleva también, una disminución del sentido de responsabilidad del propio científico respecto a las implicaciones sociales de su trabajo y a los criterios y propuestas morales que le dan orientación. La ciencia se organiza como una burocracia al servicio de las instituciones políticas y del mercado, principales poderes que gestionan el orden social y determinan los problemas y propósitos que deban guiar el rumbo de la investigación y del desarrollo tecnológico. Y mientras, la despreocupación del científico sobre tales cuestiones encuentra legitimación en los ya comentados mitos sobre la pureza de la ciencia y el progreso, supuestos ambos insostenibles una vez conocidos ciertos acontecimientos históricos que obligan a la humanidad entera a reconocer los tremendos peligros que a veces entrañan los avances del conocimiento. Pensemos solamente en los de los campos de concentración de Auschwitz y Dachau o en la explosión de las bombas atómicas de Hiroshima y Nagasaki. El sociólogo Edgar Morin señala que el aumento inaudito de conocimientos producido este siglo se ha acompañado en casi todo momento de una "ceguera característica" del investigador científico que ha hecho de su ocupación un inmejorable dispositivo para aportar al poder medios de muerte y opresión (Morin, 1984).

Pese a todo, tampoco sería sensato dar por hecho que las directrices que el Estado, el mercado o ambos sigan imponiendo al trabajo científico en los próximos años generen efectos exclusivamente negativos (tomemos en cuenta, por ejemplo, los progresos de la medicina $o$ en las facilidades que nos conceden muchos avances tecnológicos). Y ni siquiera podemos afirmar que el científico esté 
realmente legitimado para desatender las demandas de las mencionadas instituciones, dada su indudable capacidad para representar buena parte de las aspiraciones de las personas y los pueblos. Pero lo que hoy sí estamos en disposición de cuestionar es que los poderes políticos y económicos deban constituir las únicas voces con derecho o capacidad moralmente reconocidas para decidir cuáles hayan de constituir las verdaderas "demandas sociales" a las que la ciencia deba atender. Así pues, y a nuestro juicio, la necesidad de iniciar un debate sobre el compromiso viene dada por dos razones básicas. Primera, lo que podríamos llamar el estado de "inautenticidad" en que la sobreinstitucionalización de la actividad científica suele instalar al científico. Este defecto de inautenticidad es preocupante, sobre todo, porque como bien explicó el psicólogo social Ignacio Martín-Baró:

Quien se atrinchera en la negativa a optar conscientemente, sabe que sirve de hecho a aquellos bajo cuyo poder opera, es decir, a la clase dominante en cada sociedad, y ello no sólo en las aplicaciones prácticas de su quehacer, sino, más fundamentalmente, en la estructuración misma de su saber y operar científico (Martín-Baró, 1983a, p. 45).

De donde resulta el segundo argumento para reactivar un cierto debate sobre la cuestión del compromiso social del científico: la creciente desconfianza que nos inspira el proceso de instrumentalización de la ciencia al servicio de los poderes fácticos, proceso que hoy sigue su curso sin que medie en él una reflexión suficiente y sostenida acerca de la legitimidad o la ilegitimidad moral de los propósitos a los que tales poderes traten de encauzar el trabajo científico.

El debate sobre el compromiso se ha iniciado hace ya algún tiempo en diversas disciplinas de entre las que naturalmente destacan aquellas que menos inconvenientes han mostrado a lo largo de toda su historia para reconocer su carácter no neutral, así por ejemplo, la economía o las medicina y las ciencias biológicas. El desarrollo de toda una nueva disciplina como la Bioética, específicamente orientada a la reflexión moral sobre las implicaciones éticas y sociales de las ciencias médicas y biológicas resulta, de hecho, un gran avance en la dirección que también nosotros quisiéramos seguir. Pero antes deberíamos ocuparnos de algunas peculiaridades de las propias ciencias sociales 


\section{El caso particular de las ciencias sociales}

A diferencia de lo que inicialmente ocurría con las llamadas ciencias "duras", los primeros y más ilustres científicos sociales jamás disimularon la vinculación de su trabajo a intereses puramente prácticos. Así, por ejemplo, la ciencia política surge para solventar el problema del ordenamiento de la sociedad mediante el ejercicio del poder del Estado, la economía política nace para asegurar y promover el bienestar material de los ciudadanos y el incremento de las riqueza de las naciones, la sociología es una respuesta intelectual ante los trastornos y transformaciones sociales generadas a consecuencia de las revoluciones políticas e industriales de principios del siglo XIX y, al menos en parte, la psicología social nace gracias al fenómeno de las multitudes, otra nueva fuente de preocupaciones sociales y políticas que caracterizó el periodo que une el viejo XIX con el también ya concluido siglo XX. En el origen de cada una de estas disciplinas puede rastrearse alguna inquietud social a la que se pretendió dar respuesta y definición científicas sin que el abierto reconocimiento de esa preocupación o "interés" por parte del científico social fuera interpretado por éste como un obstáculo insalvable para alcanzar la tan anhelada objetividad igualmente científica.

Ahora bien, el hecho histórico de que los padres de la ciencia social concibieran a esta con una clara voluntad de servicio a la humanidad (lo cual nos permitiría hablar, entonces sí, del "compromiso del científico social") no podía garantizar y no ha garantizado de hecho la pervivencia de esa vocación emancipatoria. Aun siendo mucho más escépticos respecto a los supuestos de la pureza de la ciencia y del progreso (supuestos que la propia investigación social ha permitido denunciar como mitos), también el sentido de responsabilidad de los científicos sociales respecto a la orientación y las repercusiones de su trabajo se ha visto disminuido en muchos casos. Probablemente este hecho haya de atribuirse sólo en parte a la especialización y profesionalización del trabajo y de las instituciones científicas y en parte también a una inquietud más particular de los científicos sociales por alcanzar las mismas cotas de rigor, precisión y solidez empírica que han caracterizado a las ciencias naturales, inquietud que con frecuencia se ha denominado "cientificista" y que ha servido para anteponer a cualquier consideración o interés de tipo social o extracientífico, un auténtico "compromiso" con el método científico 
mismo, concebido éste en la mayoría de las ocasiones a la imagen y semejanza del método científico-natural.

Lo cierto es que estos dos factores (profesionalización y "cientificismo") a partir de los que hemos propuesto una primera explicación sobre el carácter insuficientemente comprometido de las ciencias sociales hemos sentado las bases que nos permitirían explicar también uno de los problemas fundamentales que actualmente aquejan a aquéllas. El problema al que nos referimos es el de la evidente fracturación que existe de hecho como consecuencia de la de la aceptación generalizada de aquella concepción del trabajo y del método científico que resulta más congruente con el celo cientificista y del enorme desarrollo que en las últimas décadas han experimentado diversas corrientes de investigación y trabajo aplicado. A consecuencia de esto, la mayoría de las ciencias sociales aparecen fracturadas en tres ámbitos de actividad diferentes. Así, de la separación tradicional entre investigación básica y trabajo aplicado surgen dos roles diferentes y dos enfoques epistemológicos, teóricos y metodológicos distintos que no siempre resultan fáciles de complementar. Así, los "aplicados" o los "técnicos" suelen reprochar en ocasiones el escaso sentido de la relevancia social que caracteriza al trabajo de los investigadores de laboratorio o encuesta - valga la simplificación-, mientras que estos últimos cuestionan el rigor con el que los primeros emplean a un nivel conceptual o técnico los conocimientos importados desde la ciencia básica.

Aunque a medida que la ciencia se transforma en tecnociencia o aspira a ello se va desdibujando la distinción entre las dos actividades que antes identificábamos con la investigación y aplicación del conocimiento (la investigación tiende a ser más aplicada, y las aplicaciones exigen una investigación más continuada), las evidentes dificultades que en muchos casos plantea la previsión de las posibilidades de aplicación del conocimiento procedente de la investigación básica, así como la pervivencia entre muchos científicos de una concepción de la ciencia como actividad absolutamente irreductible a sus aplicaciones prácticas, aún hacen útil en bastantes casos esta diferenciación clásica. Pese a todo, gran parte de los científicos sociales, ya ejerzan como investigadores o como técnicos comparten una misma idea respecto a cuál haya de ser el modo más apropiado en el que sus disciplinas debieran contribuir al desarrollo 
social y a la resolución de los problemas humanos. Conviene dejar bien claro a este respecto que esa perspectiva común sobre las relaciones entre ciencia y sociedad no es sino la resultante de una asunción directa e irreflexiva por parte de la ciencia social de los supuestos ontológicos, epistemológicos y metodológicos que tradicionalmente han definido a las ciencias naturales. Para el tema que nos ocupa habría que destacar de hecho dos supuestos de evidentes consecuencias sobre una concepción del naturalismo y el determinismo. Desde esta perspectiva, y tal y como sucede con la investigación sobre los objetos físicos, el conocimiento social no tendría consecuencias prácticas directas puesto que su generación no afectará al comportamiento del objeto estudiado. Ciertamente, tal enfoque naturalista y determinista no deja muchas opciones respecto al diseño de un modelo de aplicación del conocimiento científico social. Así, y desde el punto de vista del procedimiento, toda contribución de la ciencia social a la resolución de problemas humanos habría de concretarse en último término en alguna "intervención" de tipo técnico sobre dichos problemas, del mismo modo en que se desarrollan las aplicaciones basadas en conocimientos procedentes de las ciencias naturales.

Por otra parte, y desde el punto de vista del análisis moral, esta concepción sobre la dimensión "aplicada" de la ciencia social deja fuera de sus atribuciones cualquier cuestionamiento crítico respecto al mundo sobre el que van a operar sus "intervenciones". La conciencia moral del científico es una conciencia heterónoma, perfectamente ajustada a las directrices que provienen del ámbito extracientífico. Las obligaciones, exigencias y criterios que hayan de regular la actividad del científico, tanto en su papel de investigador como en el de técnico, quedan exclusivamente circunscritas a los estándares convencionales del rigor analítico y de la eficacia práctica. En suma, es fácil suponer entonces que en la mayoría de las ocasiones semejante perspectiva ayude a incumplir la primera condición que debiera caracterizar al proyecto de una "ciencia social comprometida", según los términos en hemos ido definiendo en páginas anteriores dicho proyecto. En vez de activar el sentido de responsabilidad de cada institución científica y particularmente de cada científico respecto a las implicaciones éticas y sociales de su trabajo, tal perspectiva limitará de forma considerable el sentido que el científico mismo pueda atribuir 
a su actividad, reduciendo su definición a los términos de una ocupación profesional idéntica o similar a cualquiera otra.

Como reacción ante la concepción anterior de las relaciones entre ciencia (social) y sociedad), surgirá un enfoque diferente que define el tercer escenario en que las propias ciencias sociales se desarrollan y que podríamos denominar como "perspectiva crítica". Tradicionalmente la idea de una ciencia social crítica ha sido vinculada a la posición teórica y las investigaciones de la ya aludida Escuela de Frankfurt, cuyos autores acuñaron la expresión de "teoría crítica". No obstante, aquí no hablaremos en principio de una "perspectiva crítica" para referirnos ni única ni principalmente a dicha escuela ni a ninguna otra. En definitiva, llamaremos perspectiva crítica a la de todos aquellos enfoques reóricos que hoy rechazan abiertamente el modelo de la ciencia natural como único modelo que deba orientar la investigación social y que, al asumir asimismo una posición crítica inicial respecto a la realidad social circundante, pretenden reintroducir en el ámbito de la propia ciencia social el mundo de los valores, exigiendo al científico social una mayor responsabilidad respecto a las consecuencias sociales de su trabajo'. En este sentido, puede decirse que tal perspectiva crítica trata de poner solución a los obstáculos que para el desarrollo de una ciencia social comprometida plantean las posiciones cientificistas adoptadas por buena parte de los investigadores y técnicos de las que hemos venido hablando en estas últimas páginas.

Pero la superación de los mencionados obstáculos no asegura tampoco la realización del proyecto de una ciencia social comprometida. Aunque las perspectivas críticas constituyen un avance y deben tomarse como modelo para hacer de la ciencia social un servicio consciente a la sociedad misma, no podemos terminar este apartado sin indicar que no todo lo que define la anterior concepción del conocimiento sostenida por investigadores y técnicos resulta prescindible o subordinable a nuestros afanes por moralizar la práctica científico social. Existe un riesgo igualmente grave que es inherente al proyecto de una ciencia social crítica y es el de la confusión de la propia actividad científica con otras formas de acción humana como la prédica moral o el mero activismo político. Es indispensable distinguir estas dos últimas ocupaciones, indudablemente necesarias en nuestro mundo, y los servicios que sólo la ciencia social puede y está en condiciones de rendir a la sociedad. Por supuesto, una vez 
superada la perspectiva cientificista y la asimilación irreflexiva del modelo científico-natural al quehacer científico social, el ejercicio de la crítica reaparece como una de las atribuciones de investigación y el análisis social, pero hemos de convenir que dicha tarea habrá de distinguirse en algo de otras formas de discurso crítico. Ante todo, la ciencia se caracteriza como dijo Zubiri, por su "voluntad de verdad", por su capacidad para acumular y sistemacizar experiencia y para extraer de ella una idea más precisa del mundo. El conocimiento es, por tanto, el objetivo primero de toda actividad científica, por mucho que luego hayamos de empeñarnos en reorientar el proceso de producción de conocimiento según ciertos objetivos prácticos y determinados propósitos morales. Pero las propias ciencias sociales enseñan que el ser humano es propenso en muchos casos a confundir sus deseos con la realidad y que incluso el científico tiende a caer en ese error. La historia entera del pensamiento social está repleta de ejemplos de ello y es evidente que ese riesgo se acentúa cuando se adopta una actitud deliberadamente crítica.

Por desgracia, la gran aceptación que en los últimos tiempos ha tenido el pensamiento "posmoderno" entre muchos científicos sociales de orientación crítica ha incrementado el riesgo del que hablamos. Sobre la base de las críticas epistemológicas a la noción convencional del conocimiento científico que la Filosofía y la Sociología del conocimiento han ido acumulando en las últimas décadas, los pensadores posmodernos han tomado como cierta (lo cual ya es paradójico en sí mismo) la imposibilidad de producir ninguna clase de conocimiento seguro, fiable o bien fundamentado. En congruencia con tal supuesto, los científicos sociales críticos apuntados al posmodernismo plantean una nueva orientación que siga aprovechando, no obstante, el prestigio y la credibilidad aún concedida a la ciencia por parte de los ciudadanos para, en nombre suyo, reforzar su dimensión crítica prescindiendo ya, eso sí, de las ataduras de la indagación empírica. Puesto que ya nadie debiera creer en la posibilidad de que la ciencia o cualquier otra forma de conocimiento aporte descripciones y explicaciones "verdaderas", el propósito de esta nueva ciencia social posmoderna sería el de promocionar aquellas concepciones del ser humano y de las relaciones sociales que favoreciesen la construcción de una sociedad más deseable. Habríamos llegado entonces a una reivindicación deliberada para igualar de modo 
definitivo a la realidad con nuestros deseos y representaciones más inmediatas, convirtiendo de hecho a la propia ciencia en un nuevo género de ficción. Por supuesto, la ficción, las novelas, la poesía y el arte han demostrado con creces su alto valor crítico y todo el mundo debe reconocer la esperanza de cambio y de reforma moral del mundo que puede alentar en ellas pero, entonces, teniéndolas a ellas, no sabríamos decir para qué diablos hubiera de servir la ciencia. Naturalmente sabemos que la realidad es misteriosa, que muestra una recia resistencia a muchos de nuestros deseos. Como decía de nuevo Zubiri, la realidad es "poderosa" y cuando en vez de ayudarnos a cumplir nuestros propósitos ese poder se ha opuesto a ellos la única forma que el ser humano ha sido capaz de doblegar a la realidad ha sido gracias a su esfuerzo sostenido por arrancar una esquirla de verdad al misterio. De ahí surge toda voluntad de conocimiento y, desde luego, la propia ciencia. No es sólo que la ciencia social no pueda ejercer compromiso alguno con la sociedad si rechaza tal vocación de conocimiento sino que, de hecho, de ja de ser ciencia.

\section{Condiciones de partida y elementos básicos para una ciencia social} comprometida

Es hora de recapitular y completar la definición de lo que podría ser una ciencia social comprometida. En primer lugar, y como acabamos de plantear, conviene exigirle al científico que no confunda su actividad con ninguna otra. Toda actividad científica ha de constituirse como un intento por arrancar a la realidad alguna porción de verdad. Este fue el sentido original del esfuerzo humano por el conocimiento y es la única justificación posible que sigue existiendo para la ciencia: la indagación de la realidad y la búsqueda de su fundamento. En el caso más concreto de las denominadas "ciencias sociales", esa necesaria "pasión por la realidad", por emplear la expresión del gran historiador de la sociología Robert Nisbett, ha sido igualmente decisiva para su nacimiento y debe seguir siéndolo en todo momento. Como científicos, antes de comprometernos con ninguna otra cosa, hemos de hacerlo con la realidad (social) inmediata, teniendo buen cuidado, por ejemplo, de no suplantarla por la "realidad virtual" de los "mercados simbólicos" o por los paradigmas de investigación, errores a los que no pocas veces parece impulsarnos el complejo mundo de la producción científica. Pensando en los 
problemas acuciantes de la realidad social centroamericana de los años ochenta (realidad no muy diferente de la actual), Martín-Baró a quien ya hicimos alusión en otro momento, hacía una recomendación a sus colegas que ilustra perfectamente la necesidad real de mantener esta primacía de realidad sobre el ámbito de las teorías y los paradigmas científicos:

A los psicólogos sociales latinoamericanos nos hace falta un buen baño de realidad, pero de esa misma realidad que agobia y angustia a las mayorías populares. Por eso, a los estudiantes que me piden bibliografía cada vez que tienen que analizar un problema, les recomiendo que primero se dejen impactar por el problema mismo, que se embeban de la angustiosa realidad cotidiana que viven las mayorías salvadoreñas, y sólo después se pregunten acerca de los conceptos, teorías e instrumentos de análisis (Martín-Baró, 1987d, p. 262).

Ahora bien, asumida su vocación de realidad ya hemos reconocido que eso no es todo. La ciencia, al igual que cualquier otra práctica social, está determinada por ciertos intereses sociales, económicos o políticos a cuya satisfacción se orientan los procesos de producción y distribución del propio conocimiento científico. La institucionalización progresiva que han experimentado todas las prácticas sociales ha convertido a la propia lógica de la investigación en un proceso puramente instrumental, en muchos casos ciego a los fines que persigue. Sabemos que esto no es bueno o malo en términos absolutos sino que será tan bueno o tan malo como de hecho lo sean aquellos fines para los que la ciencia se convierta en mero instrumento. No obstante, la experiencia indica que en verdad esos fines no han sido siempre los más razonables desde el punto de vista moral y que todo el conocimiento científico obtenido durante el pasado siglo ha hecho más bien poco por el desarrollo de un planeta más habitable, feliz y justo.

Como hemos visto, es la profesionalización de la ciencia (a la que hemos de agradecer buena parte de sus propios avances) la que hace posible, justifica de hecho la indiferencia del científico respecto a las implicaciones que tenga su trabajo más allá del ámbito del conocimiento. Esta sería, en síntesis, la antítesis del "compromiso", de la que por otro lado se puede deducir las otras dos exigencias que 
han de plantearse para su realización. Así, en segundo lugar, el compromiso del científico es imposible sin que medie una actitud "reflexiva" respecto a los intereses y fines a los que se aplica su actividad profesional. Comprometerse exige ante todo superar el estado de "falsa conciencia" en que se encuentra el científico que, en modo análogo a lo que según Marx ocurría con el proletario, aún no ha llegado a plantearse cuál es la verdadera función social que él mismo desempeña.

Naturalmente, el esfuerzo que puede implicar ese proceso de "toma de conciencia" ha de estar motivado por el propio científico, lo que significa que probablemente este no tendrá lugar a no ser que en realidad exista en él un interés real por las propias consecuencias sociales de su labor profesional. Por tanto, y como último requisito previo, el compromiso ha de presuponer también una cierta "actitud de servicio" del científico respecto a la sociedad o cuando menos una cierta inquietud moral por hacer de su trabajo, no sólo una forma de ganarse la vida, sino una actividad que facilite o influya de manera positiva en la vida de los demás.

En resumen, vocación de realidad, reflexividad y actitud de servicio son tres condiciones previas en cuya ausencia no puede darse la posibilidad de una ciencia social comprometida, sino como mucho una ciencia social sin compromiso o un compromiso no científico. Ahora bien, ni siquiera entonces está garantizada una verdadera posición comprometida por parte del científico social cuya restituida autonomía moral aun podría hacerle optar por seguir poniendo su trabajo, sus habilidades y conocimientos al servicio de los poderes establecidos, bien sea por resignación, por indiferencia (ahora conscientemente asumida) o por identificación plena con los intereses, valores y objetivos promovidos por dichas instancias de poder. Dicho de otra manera, tampoco la "autenticidad", tal vez la primera virtud moral que cabría exigirle al científico, nos asegura su compromiso profesional $e$ independiente respecto a ciertos valores e ideales morales concretos. Como advierte Victoria Camps (1983), no hay más fuente de la moral que la de la insatisfacción del hombre ante un mundo que no es perfecto pero que, al menos, podría ser mejor, más justo, más feliz. Así pues, el origen de todo verdadero compromiso no puede encontrarse en la mera relación entre hecho y valor, inherente a la estructura de la actividad científica, sino en una insatisfacción ante la 
realidad presente y respecto al papel que la ciencia ha desempeñado, por acción u omisión, en la compleja cadena de causas y efectos en que se anuda esa misma realidad. Y, ciertamente, nadie se atrevería a negar que los avances experimentados desde mediados del siglo XX hasta nuestros días en los más diversos ámbitos de la investigación científica y el espectacular desarrollo tecnológico no se han visto acompañados de un progreso suficiente en términos de relaciones humanas, justicia social o de un incremento más igualitario de la calidad de vida de la mayoría de las personas del planeta. Por el contrario, vivimos en un mundo en el que las dos terceras partes de sus habitantes sienten su futuro amenazado por el hambre o por diversas enfermedades derivadas de la malnutrición o de la falta de condiciones higiénico-sanitarias. Nuevas epidemias como las del SIDA y otras no tan nuevas incrementan a diario las tasas de mortalidad de muchas personas, especialmente las de las sociedades menos desarrolladas, al tiempo que comenzamos a prever futuros y muy graves problemas de salud que serán producidos por el progresivo deterioro ecológico en el que estamos inmersos y al que la ciencia no ha sido ajena. Subsisten aún numerosos sistemas de gobierno cuya soberanía real descansa única y asquerosamente en el poder de la fuerza, mientras que las cifras de denuncias sobre la infracción de los derechos humanos siguen siendo elevadas en todo el mundo, incluso en países que, como España, gozan de los beneficios de un sistema democrático y de un Estado de Derecho. El tráfico de armas sigue siendo uno de los negocios más solventes. La esclavitud persiste en algunos lugares en su versión tradicional en tanto que en otros contextos cobra nuevas formas (por ejemplo, el comercio con personas a través de la prostitución de adultos y niños). La religión sigue siendo en muchos casos un acicate para sostener enfrentamientos sin tregua entre los hombres y un sistema simbólico que hace del sufrimiento humano premisa irrenunciable de sus más oscuras relaciones con lo trascendente. Persisten también desde hace ya demasiado tiempo los conflictos nacionalistas, ya sean expresados por acción de grupos terroristas o se manifiesten en forma de guerras civiles que bien pueden transformarse en guerras internacionales como ha acontecido en la pasada década en el ámbito de la antigua Yugoslavia o de algunas repúblicas exsoviéticas. Tampoco hemos sido capaces de eliminar el crimen organizado ni acabar con los focos de delincuencia que constituyen verdaderos agujeros negros en casi todas las ciudades del mundo ${ }^{8}$. 
Como apunta el sociólogo Anthony Giddens (1994), resulta evidente, en definitiva, que el proyecto ilustrado fundado en la razón y la ciencia ha traído, según demuestra la historia, muy diferentes e "imprevistas consecuencias negativas". Pero si el ideal ilustrado fue el de poner la vida al servicio de la razón, parece claro que, como ya dijo Ortega hace casi ochenta años, "el tema de nuestro tiempo" más bien debiera consistir en "ordenar el mundo desde el punto de vista de la vida humana", haciendo de esta "un principio", y "un derecho" (Ortega, 1947). Y, no obstante, tanto la historia como la propia realidad presente demuestra, en palabras del teólogo Hans Küng, "que las deficiencias fundamentales de la ciencia y los grandes estragos de la técnica se eliminan con el simple recurso a más ciencia y más técnica, como (sin embargo) siguen pensando muchos artífices de la economía y la política" (Küng, 1990, p. 40). El reconocimiento de todos estos hechos, el proyecto moral de convertir la vida en derecho inalienable y en principio que justifique las evoluciones de la razón (científica o no) son los principales argumentos que podemos aportar para reivindicar una ciencia social que, formando parte de un mundo en el que la reproducción y la dignidad de la vida humana no están aseguradas para una gran porción de sus habitantes, no pretenda seguir impasible ante tal realidad. Una ciencia social comprometida.

Nuestra reflexión sobre el compromiso, no obstante, no ha hecho más que empezar. Dando por cierto que el compromiso es necesario o muy deseable conviene advertir que no existe una sola forma en la que el científico social pueda hacerlo real. Para esto habría que concretar la propuesta moral, los contenidos morales que definirían un compromiso razonable, esto es, asumible como propio por la misma comunidad científica y precisar después cuáles serían las posibilidades de su realización, es decir, el tipo de prácticas científicas que pudiera actualizar dicho compromiso. Como ya señalamos al principio, estos son los otros dos temas de discusión en torno a los cuales ha de versar un debate sobre la cuestión del compromiso (acabamos de concluir nuestra aportación al primero: su definición) y serán en consecuencia los problemas que abordaremos a continuación. 


\section{Segunda parte:}

Invitación a la ética: propuestas para el compromiso

\section{Introducción}

Volvamos al principio. Para pensar la cuestión del compromiso, dijimos entonces, era necesario que nos situáramos en el punto de vista de la moral. Recuperando la idea de Aranguren, el fenómeno moral se concretaría en tres dimensiones. Habría una "moral como estructura", una "moral como contenido" y, por último, una "moral como actitud". El acceso a este último nivel de la moral implicaría el desarrollo de un doble proceso reflexivo orientado al cuestionamiento de la moral establecida así como a la reformulación de algunos de sus contenidos o incluso a la elaboración de otros nuevos, lo que podríamos llamar una perspectiva moral autónoma.

Adoptar un cierto compromiso supone construir el proyecto moral que nos permita decidir en cada nueva situación cuál pueda ser la “mejor" posibilidad de acción de entre las varias que se nos presentan en nuestra actividad como científicos sociales, entendiendo aquélla en términos de un servicio a la vida humana. Por consiguiente, el compromiso plantea al científico un problema de razón práctica, tan diferente de la otra razón con la que está más acostumbrado a manejarse, y supone en ese sentido - tomando el título de un libro de Fernando Savater - una auténtica "invitación a la Ética".

\section{El "principio responsabilidad" y sus implicaciones morales}

Nuestro anterior análisis sobre la actual dinámica de la producción y la aplicación del conocimiento científico plantea la exigencia de promocionar una nueva ética de la responsabilidad, esto es, una ética que obligue al científico social a sopesar los posibles efectos políticos, sociales y humanos de su trabajo y que añada a sus habituales competencias intelectuales la obligación moral de prever el alcance de tales efectos. De hecho, esta es la perspectiva ética que aparece en la mayoría de los debates que abordan el problema de las relaciones entre Ética y ciencia. Las consecuencias mortales — para el hombre y también para el planeta- que ciertos avances científicos han producido durante el oscuro siglo $\mathrm{XX}$ han llevado a los filósofos morales y a los 
científicos a buscar una nueva forma de moral que planteara límites a las posibilidades de transformación de la realidad que esos avances han puesto en manos del hombre. Anticipándose a este tipo de problemas, Max Weber estableció una importante distinción entre las viejas tradiciones éticas a las que denominó "éticas de la convicción" y una nueva "ética de la responsabilidad" que debiera regir las acciones del político y el científico. Muchos años después otro pensador alemán, el filósofo Hans Jonas, propondría la promulgación de un principio responsabilidad que, asumiendo la enorme potencia de acción y de transformación del mundo que caracteriza a nuestro tiempo, nos exhortara a subordinar cualquier práctica social, incluida la de la ciencia, a una consideración sostenida respecto a todas sus consecuencias previsibles (ver Muguerza, 1990).

El principio responsabilidad es, en efecto, la exigencia que se deriva de manera inevitable de la asunción consciente por parte de todo científico de lo que el psicólogo social Tomás Ibáñez (1992) ha denominado como el "carácter politizado del conocimiento social". Esta dimensión "política" de la actividad científico social suele revelarse, según Ibáñez, en la capacidad que el propio conocimiento social muestra para inducir modificaciones en el entorno social, generalmente orientadas, eso sí, por las convenciones morales y políticas socialmente instituidas. Por esta misma razón, coincidirá Ibáñez con nosotros en la oportunidad de animar al científico social a una reflexión ética que le permita dotar de mayor autenticidad a su actividad técnica o investigadora, recurriendo a los criterios éticos y "políticos" que él considere legítimos para decidir cuál deban ser sus temas preferentes de estudio, el enfoque teórico y la metodología ideal, los resultados que deba o no deba divulgar e incluso quiénes hayan de constituir los potenciales usuarios de los conocimientos producidos. No obstante, terminará apuntando Ibáñez, y a cambio de esa libertad para determinar los valores y criterios morales que orienten su propio trabajo, será justo exigir al científico social plena responsabilidad por los posibles "efectos políticos" de aquél ${ }^{10}$.

Ahora bien, como señala el filósofo Charles Taylor (1994), la actual exaltación de esta virtud moral que llamamos "autenticidad" suele interpretarse como reivindicación de un nuevo relativismo moral que ciertamente se va extendiendo a través de las sociedades y las culturas y que constituye la consecuencia inevitable de la propia evolución de 
las naciones hacia sistemas políticos democráticos asentados además sobre una base moral no religiosa o laica. Sin embargo, nuestra reivindicación del principio responsabilidad de Jonas no pretende acompañarse de la defensa de un total relativismo de valores en las ciencias sociales. De otro modo, nuestra invitación a la ética evadiría al científico social de la responsabilidad de justificar sus "compromisos" frente a la sociedad, empezando por la comunidad científica a la que pertenece y terminando por todas las personas cuyas vidas pudieran resultar afectadas por su trabajo. Cuando uno afirma que el científico social tiene derecho a tomar sus propias opciones políticas, ideológicas y morales a la hora de estudiar la parcela de la realidad de la que se ocupa su disciplina y de poner el producto de sus investigaciones a unos u otros fines, ha de poner ciertos límites infranqueables a esa afirmación de libertad, a no ser que considere que los experimentos del doctor Mengele resultan tan legítimos, por su alto sentido de la autenticidad, como cualquier otra práctica científica.

En efecto, la ética no es sólo fruto de la introspección sino, sobre todo, del diálogo. Ninguna perspectiva moral autónoma acaba su desarrollo en el ámbito individual sino que ella misma consiste en una "propuesta moral" que siempre busca confirmación social a través de la discusión sostenida y probablemente inacabable en que culmina y se refina toda actividad racional. Es, de hecho, a esta práctica intelectual que comprende la crítica de la moral establecida, la elaboración racional de propuestas morales alternativas y la confrontación de estas propuestas entre sí a lo que más rigurosamente podemos llamar razón práctica o, más genéricamente, ética (Savater, 1982). Por tanto, exigir mayor responsabilidad moral a cada investigador, a cada técnico supone recordar también a toda la comunidad científica su deber moral de promover y participar en un diálogo abierto con los poderes públicos y privados de los que depende respecto a cuál haya de ser el sentido, el proyecto moral que pudiera justificar su propia actividad.

Indudablemente, no estamos ante una tarea fácil como lo demuestra el mismo hecho de que algunos filósofos de nuestro tiempo, sobre todo los más cercanos al pensamiento posmoderno, reconozcan haber abandonado toda esperanza acerca de fundamentar racionalmente una ética universal (ver Rorty, 1979; Bauman, 1993). Sin pretender subestimar los sesudos argumentos que estos autores aportan al debate ético contemporáneo, no podemos comulgar con su escepticismo 
moral. Si hubiéramos de creer a Wittgenstein cuando interpretó la ética como una de esas cuestiones sobre las que sería mejor "callarse", habría sido necesario que los judíos que habitaron en los campos de concentración nazis o que los indígenas que han sido masacrados en toda América durante este siglo hubiesen callado respecto a tales atrocidades (ver Dussel, 1982). Pero como ha comentado la filósofa española Adela Cortina, bajo su apariencia ingeniosa, las posturas escépticas y relativistas resultan insostenibles allí donde la moral se concreta, en la vida cotidiana de las personas, sencillamente porque "nadie puede actuar creyendo realmente que no existen unas opciones preferibles a otras, o que la maldad del asesinato y la tortura dependen de las diferentes culturas" (Cortina, 1986, p. 32).

El siguiente epígrafe aporta nuestro personal intento de participación en ese debate hipotético que antes sugeríamos a través de la recuperación de ciertos elementos de lo que podemos llamar, con Alan Bullock (1980), la tradición humanista de Occidente. Al fin y al cabo, hasta filósofos como Richard Rorty, uno de los grandes críticos de los propósitos fundamentadores de la filosofía moderna, reconocen abiertamente que en ningún modo un problema intelectual de ese tipo debería excusar nuestra participación en la tarea de promover y promocionar en el mundo una auténtica cultura de los derechos humanos.

\section{Humanismo para una ética de mínimos}

Allí donde el totalitarismo se ha instalado, la fuerza principal de resistencia que se ha movilizado contra él es la apelación al sujeto, la ética de la convicción, revista o no una forma religiosa, se llame Soljenitsin o Sajarov. Hace un siglo, Weber apelaba al triunfo de la ética de la responsabilidad sobre la ética de la convicción. Hoy, por el contrario, nuestra admiración se dirige a los que se niegan a ser buenos trabajadores, buenos ciudadanos, eficaces esclavos y que se han rebelado en nombre de una convicción religiosa o en nombre de los derechos del hombre (Touraine, 1993, p. 271).

Estas palabras del sociólogo francés Alain Touraine nos advierten sobre la insuficiencia del principio responsabilidad como criterio para orientar la acción moral del científico. El hombre siempre ha necesitado una ética de la convicción o un mínimo de convicciones o principios 
que le permitiesen distinguir entre lo que es bueno y lo que es malo, entre lo mejor y lo peor y que le indicarán algún punto hacia el que orientar sus vidas. Lo que ha variado a lo largo de los tiempos ha sido, sin embargo, las fuentes morales de las que se han nutrido las convicciones éticas humanas. Tales fuentes morales guardan una relación estrecha con las propias definiciones del hombre que han surcado la historia del pensamiento occidental y que, siguiendo a Alan Bullock (1980), podemos resumir en tres. Los seres humanos se han concebido a sí mismos, primero, como seres creados por un ser aun superior, segundo, como meros sujetos de un orden natural o ejemplares de alguna "esencia" imposible de ignorar y, por último, como individuos soberanos respecto a sus propias vidas y al mundo en que habitan. A ese tercer punto de vista, nacido con el Renacimiento y consolidado en la época de la Ilustración, se le ha venido llamando humanismo, (ver Savater, 1990).

El humanismo forzó un cambio decisivo en la perspectiva ética occidental, aunque dicho cambio no supusiera una ruptura con el tradicional supuesto de la propensión humana hacia el bien que Aristóteles concibió como justificación de la Etica, sino como una rectificación respecto a como definir lo bueno y lo malo. Intentemos explicar el sentido de esa rectificación atendiendo al problema del mal.

La determinación de lo que sea la maldad, su detección, puede entrañar un grave problema hermenéutico o de interpretación que, por ejemplo, podría forzarnos a deliberar en torno a los diversos significados que cada una de las personas implicadas en el episodio de un atentado terrorista atribuirían a semejante acontecimiento. Desde luego, la experiencia personal inmediata del sufrimiento físico o psicológico nos proporciona una primera evidencia respecto a lo que pueda constituir el mal. Sin embargo, tal evidencia no deja de ser exclusivamente personal, pues nadie puede sentir el dolor ajeno con la misma intensidad y fuerza con la que se experimenta el propio, lo cual se percibe con claridad cuando pensamos en las diferentes interpretaciones morales que el caso mencionado puede despertar en función de la "distancia" que el interpretante mantenga respecto a la víctima. Así, mientras el terrorista etarra que le descerraja dos tiros en la cabeza a un ciudadano del Estado español probablemente no hallaría maldad alguna en dicha acción, los familiares de la víctima no dudarían en condenar la crueldad injustificable de ese mismo acto. 
Ahora bien, a la hora de determinar la noción del mal conviene que planteemos la cuestión del modo apropiado, es decir, como un problema de razón práctica y no teórica, en la medida en que si bien creemos más razonable en el ejemplo anterior la interpretación de la víctima que la del verdugo, seguramente sería inexacto enjuiciar dicho conflicto de interpretaciones en términos de verdad o falsedad. Contra la vieja hipótesis de Sócrates, resulta francamente discutible que el problema de la moralidad pueda reducirse al problema de la verdad, o confundirse con él. A no ser que intentáramos una aproximación religiosa o metafísica de la ética, esto es, una ética que nos retrotrayese a un momento previo a la aparición del humanismo, cuando los hombres aún se creían en la obligación de subordinar su vida a un dogma religioso o a alguna concepción esencialista de la realidad y del mundo. Desde una perspectiva humanista, sin embargo, el problema del bien y del mal no parecen poder solucionarse hoy con definiciones últimas e inconcusas, religiosas o metafísicas, sino en todo caso mediante una deliberación racional continuada acerca de lo que, de cara a los intereses humanos, convendría considerar como bueno o malo". Y no se trata tanto de rechazar toda propuesta moral que provenga de la metafísica o la religión como de valorar esas tradiciones en función de su servicio a la vida presente y futura. Este es el punto de vista del humanismo, aquel que devuelve al hombre al centro de todas las consideraciones y que lo convierte en criterio último de todas las decisiones morales. Por supuesto, el humanismo, en prolongación de otras anteriores, ha creado su propia tradición, su propia cultura y es a ella a la que queremos volver para dar orientación moral a unas disciplinas científicas, las llamadas ciencias sociales, las cuales, de hecho, constituyen uno de los inestimables frutos a los que dio origen el propio pensamiento humanista, junto a otros como el derecho y el arte modernos o la democracia y las constituciones creadas en los dos últimos siglos.

Naturalmente, la tradición humanista aporta antes que nada el mismo concepto de bumanidad que hoy llega a nuestros oídos con fuertes connotaciones morales. Dicha noción ha servido para afirmar con mayor fuerza aún el valor incondicional del ser humano, de su libertad y de su dignidad como dimensiones irrenunciables de cualquier proyecto personal, social y político (Höffe, 1994). Además, como ha explicado Salvador Giner (1994), el humanismo se nutre de algunos 
principios morales procedentes de algunas tradiciones intelectuales anteriores como el de la "santidad de la vida humana", que luego los pensadores de la Ilustración concretarían en la afirmación de esos dos valores básicos para cualquier código ético, la dignidad y la libertad. Sobre la base de la libertad y la dignidad humanas, es decir, desde una voluntad determinada a la realización óptima de tales valores, se plantean las diversas propuestas para una ética universal o "ética de minimos" que Adela Cortina distingue de una "ética de máximos" (de la que más tarde diremos una palabra).

El primer y más valioso efecto de la afirmación de la dignidad humana es el reconocimiento de la propia humanidad en el otro, en los otros. El vehículo habitual para ese acto de identificación con el otro ha sido la compasión, sentimiento derivado de la piedad cristiana y reivindicado como virtud moral por el humanismo, constituido en muchos casos en motor de la acción humanitaria (aquella que se endereza a la erradicación del mal y del sufrimiento humanos) y sedimentado intelectualmente en el valor de la solidaridad (Savater, 1990). La importancia de este valor para configurar una ética de mínimos es también difícil de exagerar. Como ya afirmó el filósofo marxista Ernst Bloch (1980), ni las mismas carencias económicas ni las más infamantes opresiones políticas hubieran provocado transformación social alguna si los hombres que las protagonizaron no hubiera experimentado (en carne propia y ajena) ese sentimiento de dignidad herida que da origen a la solidaridad. La solidaridad constituye en suma el sentimiento piadoso o humanitario que se transfigura en valor por la invención o apropiación de la hermosa utopía de los derechos humanos.

La compasión, el reconocimiento del Otro como persona que es privada de las condiciones básicas para una vida digna y el apoyo a su derecho a denunciar tal denigración ha constituido el punto de partida de diversas propuestas éticas como, por ejemplo, las que hoy se identifican como "éticas de la Liberación", surgidas como reacción a las lamentables condiciones sociales, políticas y económicas en las que han vivido y siguen viviendo la mayoría de los ciudadanos del mundo iberoamericano (ver Höffe, 1994; Brackley, 1995; Dussel, 1998) ${ }^{12}$. Uno de los grandes méritos de estas éticas es su capacidad para poner de manifiesto como es la propia noción de dignidad, el reclamo de un derecho a una vida plena, la que propicia ese talante 
solidario y la que fomenta una primera noción de "justicia", en cuanto "justicia subjetiva" o reconocimiento de lo que debiera ser una acción correcta, o más claramente, una acción justa. De aquí desprende el humanismo su ideal de vida social que pasa, antes de nada, por la instauración de un sistema socio-jurídico que transforme esa primera forma de justicia subjetiva en una justicia objetiva, realizando así los ideales humanistas de la dignidad, la libertad y la solidaridad que han dado origen a las primeras democracias y a todas las declaraciones de los derechos del hombre y la mujer (Höffe, 1994); lo que Marina (1995) llamará el "orbe de los derechos".

El sentido de ese sistema socio-jurídico ideal, al que aspiran o deberían aspirar al menos los actuales estados democráticos, se cifra en la consecución de garantías que permitan a los ciudadanos el pleno desarrollo de sus potencialidades humanas, reconociendo de ese modo la inevitable disposición del hombre a su felicidad (ver Rawls, 1971, 1996). Sólo que, frente a la diversidad de proyectos y concepciones humanas sobre lo que pueda ser una vida buena (lo que Cortina llama las "éticas de máximos"), las atribuciones habituales de un sistema social de justicia se ocupan de una serie de necesidades universales humanas que, como hace John Rawls (1990), podemos llamar bienes primarios (o, en expresión cotidiana, "necesidades básicas") y cuya satisfacción constituyen un requisito insalvable para la búsqueda personal y/o comunitaria de cualquier proyecto de vida feliz. Empezando por el propio respeto a la vida, ese sistema sólo cobra sentido en la medida en que se ordena a la eliminación de todos los obstáculos que impiden efectivamente la satisfacción generalizada de esos "bienes primarios", obstáculos tales como la miseria, la explotación, la opresión política o la desigualdad de oportunidades de autorrealización y de trato jurídico, consideradas cada uno de esos obstáculos como "injusticias" que deben ser definitivamente erradicadas.

Un matiz importante respecto al problema de la justicia que ha sido introducido por el humanismo tiene que ver con la afirmación de la relación estrecha que aquella guarda con la conquista de nuevos ámbitos y grados de libertad real. Aunque nuestra perspectiva de ciudadanos de una sociedad política y económicamente desarrollada nos lo haga sentir como un hecho cuasi-natural, lo cierto es que el sistema de derechos y libertades de los que disfrutamos en el primer 
mundo es el producto de un largo proceso histórico de liberación de diversas formas de injusticia instituida (Ellacuría, 1990) ${ }^{13}$. La percepción de esas injusticias hubiera sido imposible, por otra parte, si el pensamiento humanista no hubiera ido desarrollado toda una serie de argumentos y principios morales que una vez sirvieron a los hombres como criterios para verificar si, en efecto, los sistemas sociales imperantes cumplían o no unos ciertos mínimos éticos basados en la libertad y la dignidad humanas. De entre esos argumentos morales merecería la pena retener al menos los más importantes o significativos:

1) La consideración del hombre como "fin en sí mismo" heredada de Kant.

2) El rechazo a toda institución social que consienta o promueva la insatisfacción de las necesidades básicas de todos los individuos para los que rija tal institución (herencia de la tradición moral y política marxiana, hoy revitalizada por las éticas de la liberación).

3) La obligación de someter toda decisión moral y/o política a la deliberación de los propios individuos que se verán afectados por dicho juicio o de tener en cuenta al menos sus necesidades e intereses personales (principio "discursivo" que forma parte central de las éticas del diálogo de Karl Otto Apel y de Jürgen Habermas).

\section{Ética de mínimos, ética de máximos}

Como acabamos de ver, la afirmación de la dignidad de todos los hombres y mujeres, base de una ética humanista y principio de una auténtica cultura de los derechos humanos mueve a la compasión y a la solidaridad y formula unas exigencias de justicia o deberes mínimos que deban ser satisfechos por cualquier sistema social.

Ciertamente, esa ética de mínimos o esos criterios de justicia son naturalmente insuficientes para orientar la actividad humana y requieren ser complementados mediante algún proyecto moral $\mathrm{y} / \mathrm{o}$ político. A esa clase de proyectos, "proyectos de vida feliz", nos referimos al hablar de las éticas de máximos. La historia entera de la humanidad ha constituido un incesante proceso de creación, implantación, y superación de otras tantas éticas de máximos o "modelos de humanidad posible" y de conflictos entre otras muchas de aquéllas (Savater, 1984; Giner, 1994) y es en parte por esto por lo que hablamos de ellas en plural. 
Pero, por paradójico que parezca, ha sido esa misma historia la que ha puesto de manifiesto el enorme riesgo que muchos de esos proyectos ético-políticos representan para la propia humanidad (Touraine, 1993). El peligro, ha comentando Cortina, aparece siempre que se intenta imponer una ética de máximos como la única razonable o legítima. En esos casos (lo han denunciado, sobre todo, pensadores posmodernos como Françoise Lyotard [1995], y tal vez haya sido éste su máximo acierto) los "grandes relatos" de emancipación que prometen una vida feliz acaban ejecutando la función de impedir que los supuestos sujetos a emancipar opinen libremente y sobre el modelo de vida que el nuevo sistema alimenta e impone.

A esa indudable propensión de gobiernos y Estados -más acentuada en unos sistemas que en otros- a fomentar la heteronomía se opone, precisamente, el modelo de sujeto (modelo ideal) del humanismo: el del sujeto con capacidad de autorreflexión y libertad normativa de su propio destino (Savater, 1990) y cuya "esencia", según Sartre (1963), sólo es el resultado de su capacidad para inventar o apropiarse libremente los valores que den sentido a su vida. Tal modelo nos lleva a recordar la constante tensión que los intereses de la sociedad o el grupo no pueden coincidir siempre y en toda medida con los del individuo (Camps, 1983; Touraine, 1993), al tiempo que afirma como forma superior de relación humana aquella que se funda en el respeto a las opiniones ajenas y en la disponibilidad a someter las propias opiniones y opciones vitales a la consideración del Otro. Modelo de sujeto y de relaciones humanas, en definitiva, que inspira el ideal de una sociedad democrática y de un Estado de Derecho y que permite al humanista plantear algunas restricciones más que razonables a los sistemas de gobierno y al Estado, limitando sus funciones a la persecución y el sostenimiento de una ética de mínimos y dejando en gran medida a los mismos ciudadanos la labor de formular y realizar en lo posible su propia ética de máximos.

Estas consideraciones tienen por supuesto implicaciones para una reflexión sobre la dimensión moral de la actividad científica. Si la perspectiva ética humanista asume y reivindica la libertad de las personas para escoger o formular su propia ética de máximos es indudable que ese derecho ha de asistir igualmente a los profesionales de la ciencia. De un lado, la prevención sobre el riesgo inherente a las éticas de máximos y la afirmación de la necesaria autonomía moral del 
ciudadano frente a tal tipo de proyectos morales y políticos proporciona un nuevo argumento para reivindicar una cierta autonomía del científico frente a los criterios morales o políticos a los que los poderes establecidos quizá pretendan subordinar su trabajo. De otra parte, debe quedar claro que esa autonomía tampoco puede ser absoluta pues es evidente que aunque estemos legitimados para conceptuarla como una virtud moral imprescindible la misma posibilidad de que optemos libremente por los criterios morales políticos o religiosos que vayan a orientar nuestra actividad como científicos no anula el riesgo de que la ciencia social se convierte en herramienta de opresión o en acicate para la injusticia. Esta es la razón por la que, de hecho, la ética plantea la necesidad de unos mínimos universales de justicia (ética de mínimos) o, más concretamente, un conjunto de valores y reglas prácticas (reglas a las que desde hace siglos llamamos "normas morales"; ver Pieper, 1991) que limiten la libertad personal en favor de la libertad y el bien(estar) de todos.

Así, podríamos atrevernos incluso a entender el compromiso del científico ( $\mathrm{y} / \mathrm{o}$ los grupos de científicos) como la concreción de su personal actitud moral en dos dimensiones diferentes y complementarias. Compromiso primero con una ética de mínimos, inviolable e universal, común a todo su gremio ( $\mathrm{y}$ al resto de los ciudadanos) y, posteriormente, compromiso opcional y variable con aquella ética de máximos que considere más oportuna. Esta perspectiva podría ofrecer una solución aproximada al problema que hoy se plantea en torno a la figura clásica del intelectual (Aranguren, 1995; Camps, 1983; Touraine, 1993; Abellán, 1994), figura o función social que tantas veces ha sido cuestionada por razón de su difícilmente evitable dependencia de los poderes políticos y económicos, aquellos mismos que crean el espacio público y las mismas condiciones de posibilidad para que el intelectual exista y ejerza como tal. En la medida en que el científico social asuma y respete esa ética mínima que quiere garantizar la vida digna de todos los seres humanos nada debiera impedirle (como no se le impide al ciudadano corriente de cualquier Estado democrático) que elija para orientar su trabajo el modelo de sociedad y el proyecto de vida personal que prefiera. 
Ética de mínimos para la ciencia social: hacia una cultura de los derechos humanos

La exigencia de una ética de mínimos universal permite identificar un punto medio entre la tradicional actitud descomprometida del científico, de la que ya hemos hablado en la primera parte de este texto, y la disposición mucho menos frecuente a adoptar un compromiso total y definitivo. Un punto medio en el que podrían situarse aquellos otros científicos que, bien por motivos claramente egoístas, bien por estar convencidos de que los compromisos morales han de tener lugar fuera de lo científico (por ejemplo, en lo político o en otros ámbitos de la vida social), aún sigan optando por esa orientación descomprometida en el marco de su profesión. En efecto, tal vez esta última actitud podría seguir siendo legítima en la medida en que hubiera una ética de mínimos que realmente funcionara como un mínimo exigible desde el punto de vista de la responsabilidad moral que todo científico estuviera obligado a asumir. Este es el sentido de los códigos deontológicos que tratan de imponerse desde hace ya algunos años en el ámbito de las diversas profesiones vinculadas al trabajo científico. No obstante, la fijación de códigos y reglas cuya infracción pudiera ser socialmente sancionada convierten el problema de la responsabilidad moral del profesional (en este caso el científico) en un asunto legal o jurídico. En muchos casos, la experiencia enseña que la consolidación de nuevas normas e instituciones orientadas a la instauración de determinados principios morales y políticos (así, los sistemas democráticos, las instituciones jurídicas o las constituciones) ha fomentado la ingenua ilusión de que ya todo estaba hecho y de que a partir de entonces los problemas se irían solucionando sin más (Cortina, 1990) cuando lo cierto es que la realización de los valores y los proyectos morales requiere, además del escrupuloso respecto a un conjunto de normas, un verdadero compromiso activo con tales valores y proyectos. Todo esto se hace aun más evidente cuando se especifican y analizan con cierto detalle los contenidos de esa ética de mínimos.

Recuperando lo dicho en páginas anteriores, hallamos diversas formas cada vez más concretas de precisar los ingredientes fundamentales para una ética de mínimos. Así, hemos identificado los contenidos de esa ética, primero, con aquellos valores fundamentales (solidaridad, justicia y autonomía) que configuran el actual "paradigma ético" de la cultura occidental (ver Rubio Carracedo 1996); segundo, 
con lo que John Rawls llama los "bienes primarios" que constituyen la base de toda justicia social en un sistema democrático's; $y$, tercero, con lo que Rorty denomina una cultura de los derechos humanos, hoy cristalizada en diversas instancias jurídicas de buena parte del mundo y en la Declaración Universal de los Derechos Humanos.

Es indudable, por ejemplo, que hoy por hoy, y pese a su extendida vigencia legal, los derechos humanos (civiles, políticos, sociales, económicos y culturales) no están totalmente garantizados en ninguna parte del mundo y que, en ciertos lugares o respecto a ciertas personas, son sistemáticamente infringidos. Por tanto, afirma Norberto Bobbio (1982), el problema actual respecto a los derechos humanos no es ya el de su fundamentación racional o el de su instauración jurídica sino el de su promoción política (de nuevo, en el sentido más amplio posible de la palabra "política"). En consecuencia, y en tanto que ingredientes fundamentales de un compromiso ético que creemos universalmente exigible a todas las personas, los derechos humanos deben ser considerados por los propios científicos no sólo como un límite cuyo trabajo no debe nunca invadir (en el sentido en que es exigible al psicólogo, volviendo al ejemplo anterior, que no emplee los conocimientos y recursos que su disciplina le proporciona para colaborar en prácticas tales como la tortura o los llamados "lavados de cerebro") sino también como un ideal de vida a promocionar y un objetivo que debiera ser antepuesto, tanto en la investigación como en el desarrollo tecnológico, a otros intereses menos urgentes o generales. Cuáles sean los caminos por los que el científico social pudiera llegar a ejercer ese compromiso es la última cuestión que abordaremos en estas reflexiones nuestras. 